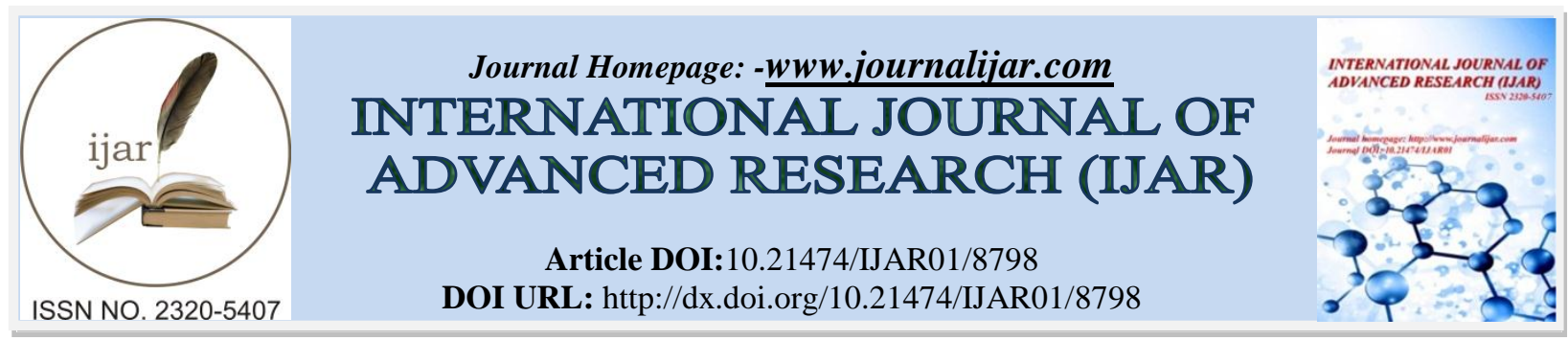

RESEARCH ARTICLE

\title{
ROLE OF ENDOSCOPY IN EVALUATING UPPER GASTROINTESTINAL TRACT LEISONS AT A TERTIARY CARE HOSPITAL.
}

Dr. Vijant Singh Chandail ${ }^{1}$, Dr. Viney Sambyal ${ }^{2}$ and Dr. Veenu Jamwal ${ }^{3}$.

1. Associate Professor Medicine, Post Graduate Department of Medicine GMC Jammu.

2. Lecturer Medicine, Post Graduate Department of Medicine GMC Jammu.

3. Associate Professor Medicine, Post GraduateDepartment of Medicine ASCOMS Jammu.

\section{Manuscript Info}

\section{Manuscript History}

Received: 03 February 2019

Final Accepted: 05 March 2019

Published: April 2019

Key words:-

Complications, endoscopy, extent of disease, pathology.

\section{Abstract}

Background and Objectives: Endoscopy as a diagnostic and therapeutic tool has grown in recent years. Upper gastrointestinal (GI) endoscopy is one of the most fascinating branch which serves not only as a means of resolving or amplifying the diagnosis made clinically or by X-ray, but also a primary diagnostic procedure for conditions not otherwise diagnosable on unoperated case. Fibre optic upper GI endoscopy has already become firmly established as a reliable, quick and inexpensive tool. This study was done to detect the upper gastrointestinal lesions in patients visiting to tertiary care hospital GMC Jammu. Materials and Methods: The study group includes patients reporting to outpatient department and also the inpatients in wards of General Medicine and other departments, who have upper GI symptoms, were advised endoscopy at GMC Jammu, from a period of March 2016 to August2018. Results: Of the 6438 cases, 3862 were males, and 2576 were females. Disease incidence was highest in 41 to 50 years age group that is $24.9 \%$. Pain abdomen was the most common symptom. Epigastric tenderness was the most common sign among the patients clinically. Antral Gastritis formed most common cases (1084 cases). The incidence of duodenitis - $2.1 \%$, duodenal ulcer $-5.6 \%$, esophageal varices $-13.5 \%$, the incidence of carcinoma esophagus and carcinoma stomach was approximately $6.8 \%$ and $4.2 \%$ respectively. The incidence of esophageal candidiasis was $0.6 \%$. The majority of the patients had a normal study that is $10.1 \%$. Conclusion: Upper GI lesions were more common in males. The incidence of diseases was highest among the elderly age group. Most of the benign mucosal lesions were mainly due to spicy food and habit of tobacco consumption. The incidence of malignancy was mostly among older age group above 50 years. The incidence of the normal study was high owing to increased medical care, easy availability of the procedure and increased medical awareness among patients. In all these cases, upper GI endoscopy not only helped in diagnosing the disease but also helped to get information about pathology, extent of disease and complications that have occurred. This study highlights the importance of diagnostic and therapeutic uses, recording of the various gastroenterological diseases we come across in population. 


\section{Introduction:-}

India is a developing country with one of the most diverse populations and diets in the world. Gastrointestinal (GI) tract related abnormalities in India are rising (increasingly being reported) with increasing migration of rural population to, the cities and a change in lifestyle.

Diagnosis and localization of its afflictions relied for many decades on barium radiology, which provides indirect data in black and white. The situation has changed dramatically since the late 1960s with the introduction of fully flexible and manoeuvrable endoscopes. Upper gastrointestinal (GI) lesions include patients presenting with symptoms of acid-peptic disease recurrent vomiting, dysphasia, hematemesis, etc., The prevalence of gastroesophageal reflux diseases is more in western countries compared to Asia. The complications such as duodenal ulcers and strictures, Barrett esophagus and esophageal adenocarcinoma, can be greatly reduced if early diagnosis and screening are done by endoscopy. $[1]$

Peptic ulcer (duodenal and gastric ulcer) is common in men and prevalence is increased with age with a peak prevalence of $28.8 \%$ in $5^{\text {th }}$ decade of life. ${ }^{[2]}$ The role of endoscopy in bleeding peptic ulcer disease is significant. It is an effective tool in diagnosis, prognostication, and therapy of bleeding peptic ulcer.

The studies have shown that endoscopic intervention has led to a reduction in a blood transfusion, shortened Intensive Care Unit and hospital stays. It has decreased the need for surgery and lowered the mortality rate. ${ }^{[3],[4]}$

We routinely encounter patients with upper GI symptoms. Hence, the need for the study is early detection of upper GI lesions by endoscopy and later evaluating the disease for appropriate management.

\section{Materials and Methods:-}

This is a retrospective study conducted in 6438 cases at G.E division of department of Medicine, Govt: Medical College Jammu during the year March 2016 to August 2018.

In all the cases, the endoscope used was OLYMPUS JAPAN EVIS Exera III CV-190 processor with GIFH190 Gastro scope and GIFXP190N PaediatricGastroscope.

Patients were selected at random for the study and fell into two categories:

- Inpatients-referred and emergency

- Outpatients received through OPD.

All indoor and outdoor patients who were referred for upper GI endoscopy were included in this study.Informed consent were taken from all the patients.

In some of the cases, the radiological examination was done prior to endoscopy.

\section{Investigations}

following investigations were routinely done before endoscopic examination:

1. Haemoglobin

2. Stool for occult blood

3. LFT in jaundice.

4. Ultrasound abdomen

5. Chest $\mathrm{X}$ ray $\mathrm{P} / \mathrm{A}$ view

6. ECG all leads

7. Complete blood count

8. Barium examination (if necessary).

The examination was carried out under local anesthetic solution using lignocaine viscus $2 \%$ spray, sprayed 5 min before the procedure. 
Since fiberoptic endoscopy is simple and safe, we did not encounter any complications. Inadequate or improper explanation makes patient apprehensive, this is true especially with children and elderly. It is most important to have patient's co-operation to complete the procedure safely. Both safety of the patients and instrument are important for the endoscopist.Endoscopic biopsy wherever necessary was taken and sent for histopathology.

\section{RESULTS}

Of the 6438 patients studied, the maximum numbers of patients belonged to the age group of 41 to 50 yrs were 1609 (24.9\%). The minimum number of patients studied belonged to the age group of 1-10 years constituting 107 cases $(1.7 \%)$.

Of the 6438 patients studied, 3862 patients were males (59.99\%) and 2576 were females $(40.01 \%)$. Of the 6438 cases studied, it has been observed that the maximum number of GI lesions was in the stomach followed by esophagus and duodenum. Malignant lesions of stomach and esophagus were seen in 273(4.2\%) and 437(6.8\%) cases respectively. Only 6 cases (0.09) of carcinoma duodenum were seen in our study.

\section{Distribution of malignant lesions of the upper gastrointestinal tract}

Out of 6438 cases studied, 716 cases were diagnosed on endoscopy as malignant lesions. Of the 716 cases studied 273 cases were carcinoma stomach, of which 196 were seen in males, 77 were seen in females.

437 cases were carcinoma esophagus, of which 283 were seen in males, 154 were seen in females.

This is a prospective study conducted in Department of General Medicine from March 2016 to August 2018 at Govt: Medical College Jammu. 6438 cases that fulfilled the inclusion criteria were included in the study and were subjected

In the present study, maximum number of cases subjected to endoscopy belonged to the age group of 41 to $50 \mathrm{yrs}$ (24.9\%) and 51-60 years (21.9\%). In a similar study by Ray and Pal done at Referral Railway Hospital, Kolkata, the mean age group of the study was 51-60 years. ${ }^{[5]}$

In the present study, the maximum patients subjected to endoscopy were males (59.9\%). In the study by Naniwadekar and Kuwait series maximum numbers of patients subjected to endoscopy were males (72.5\% and 62\% respectively). The results were similar to our study. ${ }^{[6,[7]}$

In this study, most of the patients on upper GI endoscopy were found to have Gastritis. The incidence of esophagitis and Antral gastritis was $3.6 \%$ and $16.8 \%$ respectively, our results are comparable to study done by Ray and Pal and Shennaketal

Gastric ulcer incidence was low about 2.6\% compared to other studies by Al-Nakib and Al-Liddawi and Ray and Pal which was $5.9 \%$ and $4.9 \%$. This may be attributed to the widespread use of proton pump inhibitors in the elder age group people as PPI are co-prescribed with NSAID'S and antiplatelet agents used for cardiovascular, cerebrovascular and rheumatological diseases. Also, the PPI are available easily over the counter and people are now more aware of GI symptoms.

The incidence of gastric carcinoma in our study was found to be $4.2 \%$. The incidence of gastric carcinoma was $6.5 \%$ in a study by Ray and Pal. These finding were similar to studies done by Lambert and Ferlay (8, 9). Antral gastric carcinoma was more predominant compared to carcinoma of the stomach in body and fundus.

The incidence of carcinoma esophagus was $6.8 \%$ in our series. Incidence pattern is comparable with the incidence of $6.6 \%$ and Ray and Pal with the incidence of $4.6 \%$. Out of the total 437 cases, 283 were Males and 154 were Females. In males, the maximum patients affected were in the age group of 60 years and above.

Esophageal Candidiasis in the present study, Incidence was $0.6 \%$, that is, 39/6438. It was seen more common among the male of the age group 50-60 years of the affected individuals. Only 6 of them were sero-positive for HIV. Candidiasis also affected other individuals (who were not sero-positive for HIV), this may be attributed to the advanced age, diabetes mellitus, alcoholism, inhaled gluco-corticoid use in asthmatics and acid suppressive therapy for patients with chronic gastritis. ${ }^{[10],[11]}$ Total numbers of normal study cases were 649 and incidence was $10.5 \%$. 
Incidence was more in females compared with males. The normal study were more compared to all previous studies ${ }^{[12]}$ The increase in normal studies of endoscopy on recent years is mainly because of increased medical care, easy availability of the procedure and increase awareness of health among the population.

The incidence of upper GI lesions namely gastroduodenitis, duodenal polyp were $3.4 \%$ and $0.3 \%$ respectively. We had 20 cases $(0.3 \%)$ of stricture esophagus following corrosive acid consumption. [13]

TABLE NO:1 --DISTRIBUTION OF PATIENTS ACCORDING TO AGE

\begin{tabular}{|l|l|l|}
\hline AGE GROUP (in yrs) & NUMBER OF PATIENTS(N) & PERCENTAGE $(\%)$ \\
\hline $1-10$ & 107 & 1.7 \\
\hline $11-20$ & 284 & 4.4 \\
\hline $21-30$ & 791 & 12.3 \\
\hline $31-40$ & 1326 & 20.6 \\
\hline $41-50$ & 1609 & 24.9 \\
\hline $51-60$ & 1408 & 21.9 \\
\hline 61 -above & 913 & 14.2 \\
\hline Total & 6438 & 100 \\
\hline
\end{tabular}

TABLE NO: 2 --DISTRIBUTION OF PATIENTS ACCORDING TO SEX

\begin{tabular}{|l|l|l|}
\hline SEX & NUMBER OF PATIENTS(n) & PERCENTAGE $(\%)$ \\
\hline MALE & 3862 & 59.99 \\
\hline FEMALE & 2576 & 40.01 \\
\hline & 6438 & 100 \\
\hline
\end{tabular}

TABLE NO: 3--DISTRIBUTION OF PATIENTS ACCORDING TO ETIOLOGY

\begin{tabular}{|l|l|}
\hline ESOPHAGEAL FOREIGN BODY & $43(0.7)$ \\
\hline REFLUX ESOPHAGITIS & $229(3.6)$ \\
\hline REFLUX ESOPHAGITIS WITH GASTRITIS & $183(2.80)$ \\
\hline ESOPHAGEAL VARICES & $864(13.5)$ \\
\hline MALLORY WEISS TEAR & $66(1)$ \\
\hline ESOPHAGEAL CANDIDIASIS & $39(0.6)$ \\
\hline ESOPHAGEAL STRICTURE & $21(0.3)$ \\
\hline ESOPHAGEAL CARCINOMA & $437(6.8)$ \\
\hline BARRET ESOPHAGUS & $93(1.4)$ \\
\hline HIATUS HERNIA & $248(3.9)$ \\
\hline PANGASTRITIS & $102(1.6)$ \\
\hline GIST & $54(0.8)$ \\
\hline DIEULAFOY LEISON & $9(0.1)$ \\
\hline ANTRAL GASTRITIS & $1084(16.8)$ \\
\hline FUNDAL AND ANTRAL GASTRITIS & $318(4.9)$ \\
\hline DUODENO-GASTRIC BILE REFLUX & $211(.3)$ \\
\hline GASTRIC ULCER & $161(2.6)$ \\
\hline GAVE & $56(0.9)$ \\
\hline GASTRIC VARICES & $94(1.5)$ \\
\hline PYLORIC STENOSIS & $49(0.8)$ \\
\hline DUODENAL ULCER & $362(5.6)$ \\
\hline DUODENAL VARIX & $5(0.1)$ \\
\hline CARCINOMA STOMACH & $273(4.2)$ \\
\hline FOREIGN BODY STOMACH & $7(0.1)$ \\
\hline DUODENITIS & $136(2.1)$ \\
\hline GASTRODUODENITIS & $218(3.4)$ \\
\hline DUODENAL POLYP & $19(0.3)$ \\
\hline WORMS & $49(0.8)$ \\
\hline & \\
\hline
\end{tabular}




\begin{tabular}{|l|l|}
\hline CARCINOMA DUODENUM & $6(0.09)$ \\
\hline GASTRIC POLYP & $63(0.9)$ \\
\hline DUODENAL DIVERTICULA & $48(0.7)$ \\
\hline EXTRINSIC COMPRESSION ESOPHAGUS & $15(0.2)$ \\
\hline EXTRINSIC COMPRESSION STOMACH & $36(0.6)$ \\
\hline EXTRINSIC COMPRESSION DUODENUM & $7(0.1)$ \\
\hline ESOPHAGEAL CORROSIVE INJURY & $71(1.1)$ \\
\hline STOMACH CORROSIVE INJURY & $33(0.5)$ \\
\hline CORROSIVE INJURY-BOTH & $48(0.7)$ \\
\hline NORMAL & $649(10.1)$ \\
\hline ESOPHAGEAL POLYP & $8(0.1)$ \\
\hline GASTROJEJUNOSTOMY & $24(0.3)$ \\
\hline TOTAL & $6438(100)$ \\
\hline
\end{tabular}

TABLE NO:4 DISTRIBUTION OF MALIGNANT LEISONS OF UPPER GIT

\begin{tabular}{|l|l|l|l|l|}
\hline TYPE \&SITE & MALE $(\mathrm{n})$ & FEMALE $(\mathrm{n})$ & TOTAL $(\mathrm{n})$ & PERCENTAGE $(\%)$ \\
\hline Ca Stomach & 196 & 77 & 273 & 4.2 \\
\hline Ca Esophagus & 283 & 154 & 437 & 6.8 \\
\hline Ca Duodenum & 5 & 1 & 6 & 0.09 \\
\hline \multicolumn{1}{|c|}{ Total } & 484 & 232 & 716 & 11.1 \\
\hline
\end{tabular}

\section{Conclusion:-}

Upper GI lesions were more common in males. The incidence of diseases was highest among the elderly age group. Most of the benign mucosal lesions were mainly due to spicy food and habit of tobacco consumption. The incidence of malignancy was mostly among older age group above 50 years. The incidence of the normal study was high owing to increased medical care, easy availability of the procedure and increased medical awareness among patients. In all these cases, upper GI endoscopy not only helped in diagnosing the disease but also helped to get information about pathology, extent of disease and complications that have occurred. This study highlights the importance of diagnostic and therapeutic uses, recording of the various gastroenterological diseases we come across in population.

\section{References:-}

1. Vakil N, van Zanten SV, Kahrilas P, Dent J, Jones R; Global Consensus Group. The Montreal definition and classification of gastroesophageal reflux disease: A global evidence-based consensus. Am J Gastroenterol 2006; 101:1900-20.

2. Khuroo MS, Mahajan R, Zargar SA, Javid G, Munshi S. Prevalence of peptic ulcer in India: An endoscopic and epidemiological study in urban Kashmir. Gut 1989; 30:930-4.

3. Barkun A, Bardou M, Marshall JK; Nonvariceal Upper GI Bleeding Consensus Conference Group. Consensus recommendations for managing patients with nonvariceal upper gastrointestinal bleeding. Ann Intern Med 2003; 139:843-57.

4. Spiegel BM, Vakil NB, Ofman JJ. Endoscopy for acute nonvariceal upper gastrointestinal tract hemorrhage: Is sooner better? A systematic review. Arch Intern Med 2001; 161:1393-404.

5. Ray G, Pal S. Trends in endodiagnosis of upper gastrointestinal diseases at a referral railway hospital. J Dig Endosc 2011; 2:213-9.

6. Al-Nakib B, Al-Liddawi H. Upper gastrointestinal endoscopy experience in Kuwait: Analysis of 1019 cases. GastrointestEndosc 1981; 23:605-7.

7. Shroff CP, Nanivadekar SA. Endoscopic brushing cytology and biopsy in the diagnosis of upper gastrointestinal tract lesions. A study of 350 cases. ActaCytol 1988; 32:455-60.

8. Lambert R (2013) Role of Endoscopy in Screening and Treatment of Gastrointestinal Cancer. J Gastroint Dig Syst S2:006. doi: 10.4172/2161-069X.S2-006.

9. Ferlay J, Shin HR, Bray F (2010)_Cancer Incidence and Mortality Worldwide: IARC Cancer Base No. 10. IARC Lyon.

10. Mimidis K, Papadopoulos V, Margaritis V, Thomopoulos K, Gatopoulou A, Nikolopoulou V, et al. Predisposing factors and clinical symptoms in HIV-negative patients with Candidaoesophagitis: Are they always present? Int J ClinPract 2005;59:210-3. 
11. Underwood JA, Williams JW, Keate RF. Clinical findings and risk factors for Candida esophagitis in outpatients. Dis Esophagus 2003; 16:66-9.

12. Shennak MM, Tarawneh MS, Al-Sheikh TM. Upper gastrointestinal diseases in symptomatic Jordanians: A prospective endoscopic study Ann Saudi Med 1997;17:4.

13. Contini S,ScarpignatoC.Caustic injury of the upper gastrointestinal tract :a comprehensive review.World J Gastroenterol.2013;19(25):3918-30. 